\title{
Review-based Emergy Analysis of Energy Production
}

\author{
Ginta Cimdina, Toms Prodanuks, Dagnija Blumberga, Ivars Veidenbergs, \\ Riga Technical University, Institute of Energy Systems and Environment. \\ Address: Azenes street 12/1, Riga, LV-1048, Latvia
}

\begin{abstract}
The role of power and thermal energy is impossible to overestimate in development of both state economy sector and everyday life of households. Importance is connected with use of resources, economical feasibility and effect to climate changes. The optimization of energy production allows to promote development of sustainable society. The most popular and efficient technologies for generation of power and thermal energy are cogeneration plants (CHP). Traditional evaluation methodologies of energy production systems are based on analysis of energy and mass balances as well as on cost analysis. It is not enough for assessment of complete sustainability of system. Necessary environmental impact assessment of energy production is possible to implement by use of emergy analysis. Definition of emergy includes one type of energy, which is used directly or indirectly to produce materials, provide services and finances. Emergy dimension is emjoules (seJ.). Paper presents case study of emergy analysis of different operation modes of one cogeneration plant.
\end{abstract}

Keywords: Emergy analysis, cogeneration, sustainability.

\section{INTRODUCTION}

Traditionally, for the purposes of analysis of energy production systems, the energy, mass flow and economic analysis methods are applied; however, nowadays, as the topic of sustainable system development is on the rise, the analysis must also integrate environmental impact assessment methods. Emergy analysis, which is being successfully applied for the analysis of energy production systems, could be given as an example of such an integral assessment method [1, 2]. Emergy is defined as the available solar energy that has previously been directly or indirectly used to make a product or provide a service [3]. The unit of emergy is the emjoule (sej) and it represents the energy incorporated in a product or service. Emergy time units sej/s or sej/yr are called emergy flow or empower. Compared to energy analysis, emergy analysis is more versatile and has wider boundaries. It addresses not only energy and material flows, but also information, services, finance, labor, as well as changes to the environment caused by the production process. Assessment is expressed in a single energy unit - the sej. One could say that emergy analysis is ecology-driven, if compared to energy analysis, which is human-focused. Actually, emergy is a means to determine the amount of work contributed by the biosphere for a company to produce a particular product. Accordingly, emergy analysis is a way to describe a company in the long run and within a wider space (biosphere), i.e. to assess its sustainability [4]. Company sustainability is difficult

to assess and quite often it is reasonably judged by presuming that the more renewable energy a company uses, the more sustainable it is. It is increasingly forgotten that fossil fuels are being consumed in order to extract, transport and process renewable resources, which is why it is necessary to analyze the entire energy production chain and determine the net energy gain. The damage caused to the environment as a result of using these resources should also be taken into account.

Net energy gain is energy contained within the resource (taking into account the environmental impact, labor costs, consumption of materials, etc.) minus fossil fuel energy consumed. As a result of such a net energy gain assessment, it may turn out that fossil fuels are more sustainable when compared to the use of renewable resources [5].

In energy production, the environment is used in various ways [6]:

- it provides energy resources;

- it absorbs emissions;

- it provides cooling for various processes by means of water or air;

- it provides oxygen for combustion processes.

The aforementioned 'services' put a burden on the environment and shall be assessed to determine the sustainability of energy production. The concept of environmental loading is based on the opinion that when using an environmental service, it is not available to another user. The environment has a certain service accumulation capacity that regenerates 
if the load does not exceed the permissible values. Exceeding the permissible environmental loads kicks off an irreversible degradation process within the local environment. It is clear that the sustainability assessment of the energy production process must include the analysis of net energy gain, environmental loading and production emissions, which enter the environment.

Emergy analysis is based on the principles of thermo-dynamics, system theory, system ecology [6]:

- it serves as a link between the system economic and ecological assessments, allowing their objective comparison thanks to a single assessment;

- by using specific indicators, it determines the environmental impact of the system and processes;

- it studies how renewable the resources used are. This is determined by the amount of work required by the ecosystem for the resources to regenerate;

- it evaluates the quality of flows in terms of quantity, which is particularly important for flows that do not have market monetary value;

- it determines the emergy per monetary unit and labour unit;

- it studies the amount of environmental services required to ensure the functioning of the system and processes;

- compared to other methods (life-cycle analysis, exergy analysis, entropy analysis), it provides more complete and quantitative information for making environment-related decisions; emergy analysis covers the entire system, instead of just individual parts or processes.

It has been noted that emergy analysis has a significant deficiency, namely, the necessity of solar energy conversion data for a wide range of services and products. Database accuracy and completeness influence the results of emergy analysis.

\section{EMERGY ANALYSIS METHODOLOGY AND INDICATORS}

In energy analysis various forms of energy can be expressed as coal, oil or another given fuel, and these can be compared. This is, however, impossible as regards the materials, services or labour necessary for the energy production process. Yet, each of the input quantities required in the energy production process has its own energy value, which has been consumed in the production or in ensuring economic resources created by the production process, and this value should be taken into account in assessing the energy production process. When using emergy calculations, the aforementioned input values can be calculated in comparable units - sej/J; sej/€; sej/kg, etc. and with their help it is possible to determine the total emergy necessary for the production process. An overall chart of the production system and the symbols used in emergy analysis are presented in Figure 1. The chart shows the input resources required for the process and the obtained product output, as well as the flow interaction within the process.

In the chart, by means of the larger square, the local system has been isolated from the biosphere; the smaller square represents the production process. The flows that cross the boundaries of the production process are used for the calculations. The production process uses two environmental resources:

- $\mathrm{R}$ - renewable natural resources, which in turn are divided into two groups:

- renewable R1, which include solar energy, wind energy and rain;

- renewable R2, which are related to local ecosystem-provided resources such as renewable energy resources (biomass), as well as water and air in process-cooling equipment. Air is also used in combustion processes.

- $\quad \mathrm{N}$ - non-renewable natural resources, including coal, gas, oil products or groundwater if used faster than its regeneration rate.

Input F contains economy-ensured services related with the development and operation of the production process, services, technical equipment, remuneration, etc. Total $\mathrm{Y}$ emergy is attributed to the process end product (output) and is labeled Y. The production byproduct (pollutant) flow is labeled with $\mathrm{W}$, and it penetrates the environment. Using the examined flows, the following indicators are defined for each production process (company): 


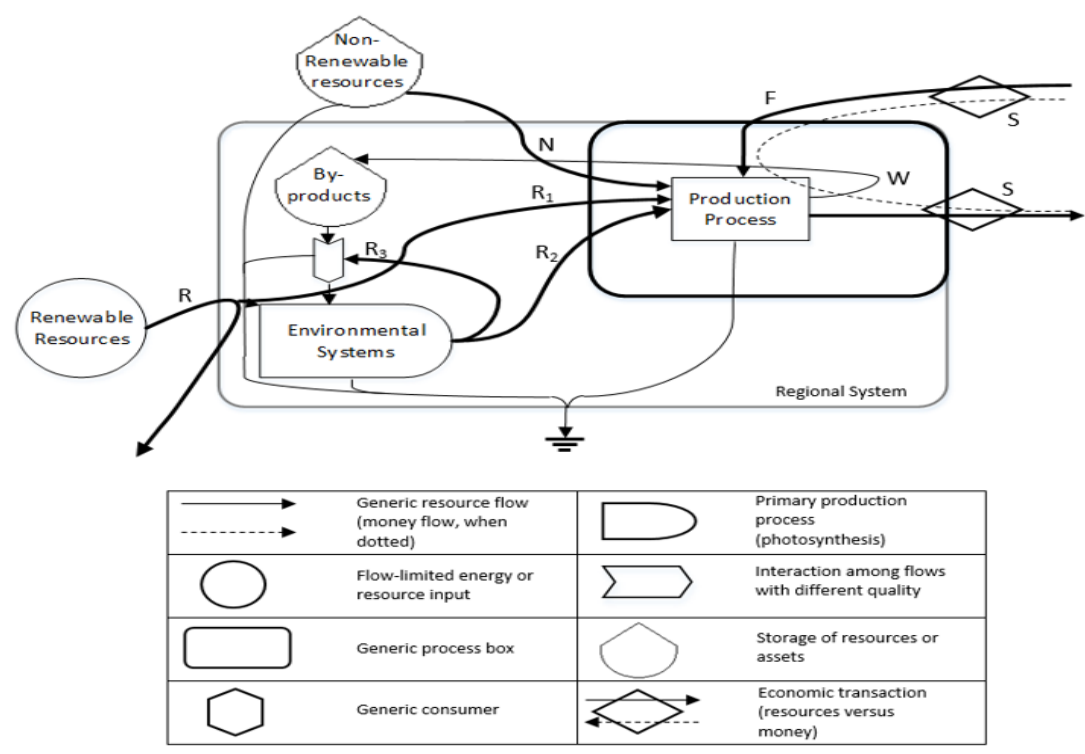

Fig. 1. Overall system chart and symbols used

1. Emergy yield ratio (EYR). The emergy yield ratio describes the benefit of various production processes to the general public. The bigger the share of local renewable $(\mathrm{R})$ and non-renewable resources $(\mathrm{N})$ per unit of external (F) investment, the bigger the EYR value and the more the facility is focused on local resources. The indicator does not evaluate whether or not the resources are renewable or non-renewable; it determines whether the emergy is of local $(\mathrm{Y})$ origin or imported from outside $(F)[7,8]$.

$$
E Y R=\frac{Y}{F}=\frac{F+R+N}{F}
$$

2. Environmental loading ratio (ELR). The use of environmental services to ensure the production process is defined by the environmental loading ratio. If the indicator is high, it means the production is significantly affecting the environment and that it uses mainly emergy from non-renewable resources. It also means that there is substantial use of economyprovided resources $F$. If the emergy yield ratio (EYR) is increasing due to intensive use of renewable resources, the environmental loading ratio decreases and the level of production environmental loading is low. In turn, if the EYR is increasing because the amount of external (economy) services is growing, then the environmental loading ratio (ELR) will also increase and the production process will exert a greater load on the environment $[9,10]$.

$$
E L R=\frac{F+N}{R}
$$

3. Emergy sustainability index (ESI). The emergy sustainability index is a ratio between the emergy yield ratio (EYR) and the environmental loading ratio (ELR). It is recommended to achieve a higher emergy yield ratio (EYR) with less environmental loading. For the production process to be sustainable, the emergy sustainability index (ESI) value must be above 1 .
Should the ESI value fall below 1, this means that the production process,

product or economy is not sustainable in the long term [4].

$$
E S I=\frac{E Y R}{E L R}
$$

4. Empower density (ED). Emergy density (ED) describes the intensity of an activity (process, product, economy) and allows the comparison of activities.

$$
E D=\frac{F+R+N}{\text { unit }(J ; k g ; \text { etc }) \text {.time }}
$$

5. Renewable share $(\mathrm{R})$ in percentages. Renewable share in percentages $R$ defines the share of renewable resources in the production of the final product. Processes with a higher percentage are more sustainable since they are using more renewable resources.

$$
R=\frac{100 \cdot R}{F+R+N}
$$

6. Emergy investment ratio (EIR). The emergy investment ratio describes the economy-developed investment $\mathrm{F}$ in the production process that uses local renewable resources $(\mathrm{R})$ and non-renewable resources $(\mathrm{N})$. The ratio compares the input $(\mathrm{R}, \mathrm{N})$ required for the process with the input from the process environment F. A high EIR value indicates a significant contribution from the economy in ensuring the production process, and it is also subject to changes in the economy. A low EIR value means that the production process is beneficial for the economy and confirms the existence of an investment-friendly environment. It is observed that with the reduction of the use of non-renewable resources $\mathrm{N}$, the EIR value moves towards the environmental loading ratio (ELR) value. 


$$
E I R=\frac{F}{R+N}
$$

7. The unit emergy value (UEV) is used for the emergy calculations of processes, which is expressed as follows [11]:

$$
U E V_{i}=\frac{S}{F_{i}}
$$

S - annual emergy of the process (sej/yr);

where

$F_{i}-\mathrm{i}$ : annual flow of the particular resource (g/yr, $\mathrm{m} 3 / \mathrm{yr}, \mathrm{J} / \mathrm{yr}$, etc.).

The unit emergy value (UEV) is a conversion factor used to determine the emergy of any service or product, and its value is determined by analysis or taken from data provided in the literature. Where the UEV is attributed to the resource mass flow, it is often called the specific emergy and its measurement unit is sej/g. In turn, if the resource flow is expressed in energy units, then the UEV is called transformity and its measurement unit is sej/J [12].

The chart in Figure 1 is used to develop a detailed chart of production process flows, which is used as a basis for process emergy calculations.
Uncertainty in emergy analysis is significantly affected by two [13]. The first is the insufficient and inaccurate unit emergy value (UEV) data available in the literature, which primarily deals with industrial products and transport systems and demonstrates mainly generic or approximate indicators..

The next source of uncertainty is the inaccurate inventory of a process and the incomplete assessment of process input. For instance, emissions from the production process exert a load on the environment, which must be assessed. This requires information on the condition of the region's ecosystem, which in turn requires a separate study and assessment.

When carrying out emergy calculations and using data from unit emergy value (UEV) literature, it is important to carefully follow the data origins and the chain of calculations in order to avoid the double inclusion of emergy. One potential option is to use data on the total impact of the biosphere, excluding the impact of individual chain sections.

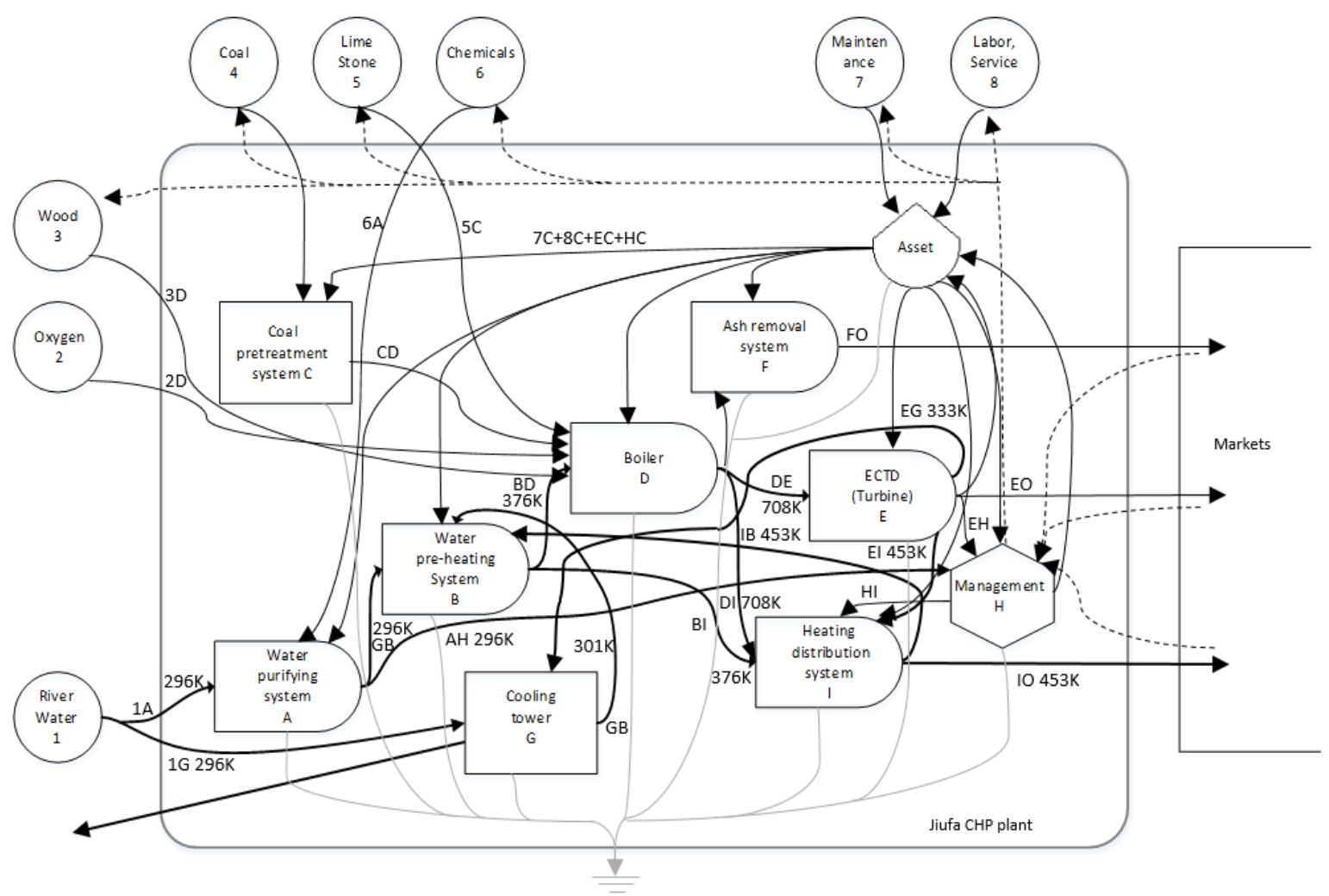

Fig. 2. Co-generation plant energy flow chart with input and output data [14] 


\section{EXAMPLE OF EMERGY ANALYSIS FOR THE PRODUCTION OF CO-GENERATION ENERGY}

Energy production processes and technologies differ both in terms of input (different energy resources, water source) and output (heat or electricity generated). In order to achieve a more complete analysis result, a co-generation plant generating both energy types was selected. Emergy analysis of cogeneration plants and comparison with coal and biomass uses $[14,15]$.

The case study for emergy analysis of cogeneration plant (CHP) data is implemented by use of data published in paper [14]. Emergy calculations are done for three different operation modes of cogeneration plant fuelled by coal.
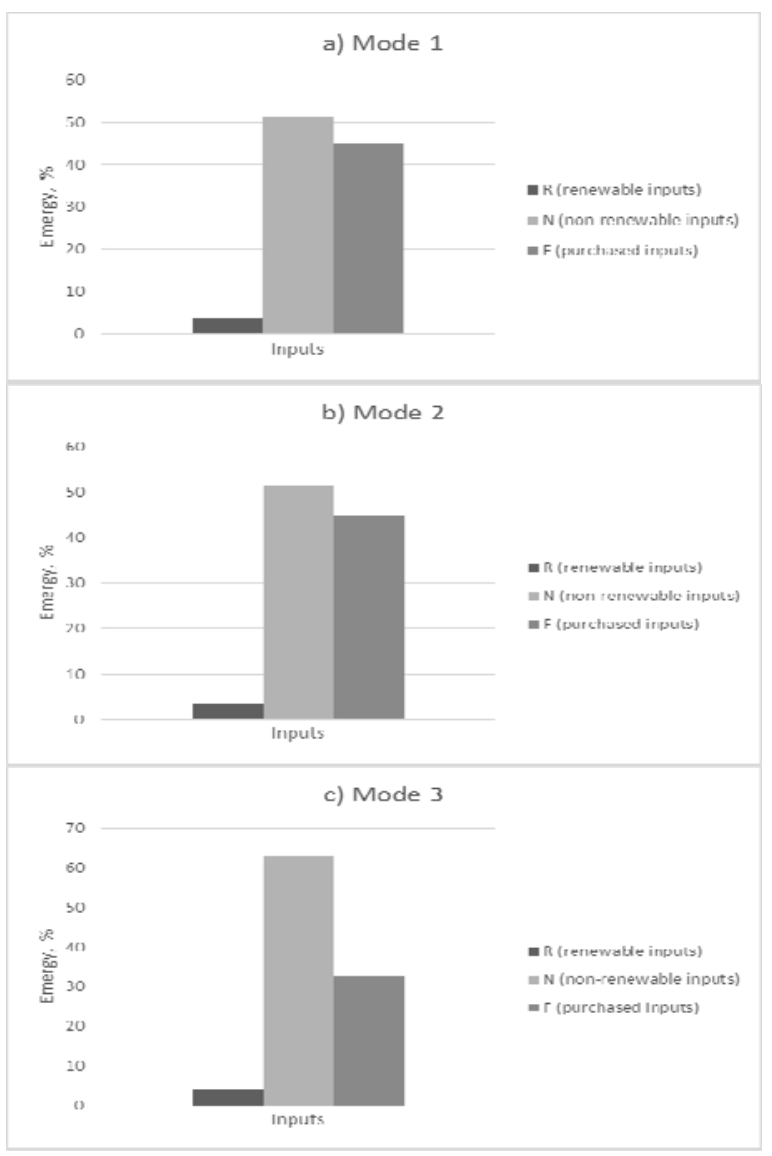

Fig.3. Emergy shares for resources of CHP

Results of cost benefit analysis of three operation modes are presented in Figure 4.

Mode 1 presents the operation of cogeneration plant in the case when steam produced by the boiler is used for power generation and only some part of thermal energy production (other part is cooled in cooling tower of CHP). It means no possibility to use all potential thermal energy because of lack of heat load.
Mode 2 presents the integration of cogeneration plant in regional energy supply system and increase of heat load of CHP. It allows to use steam energy completely without application of the cooling tower. Power load changes are not observed.

Mode 3 presents the operation of cogeneration plant with installed power and heat energy capacity without use of the cooling tower.

The results of emergy and economic analysis of three operation modes of the cogeneration plant fuelled by coal are presented in figures below. Comparison of three operation alternatives show that emergy of renewable resources input is similar in all three operation modes. Different is situation with emergy of non-renewable resources: in the Mode 1 and Mode 2 emergy is similar and it is increasing in Mode 3. Emergy of purchased inputs is lower in the third operation mode.
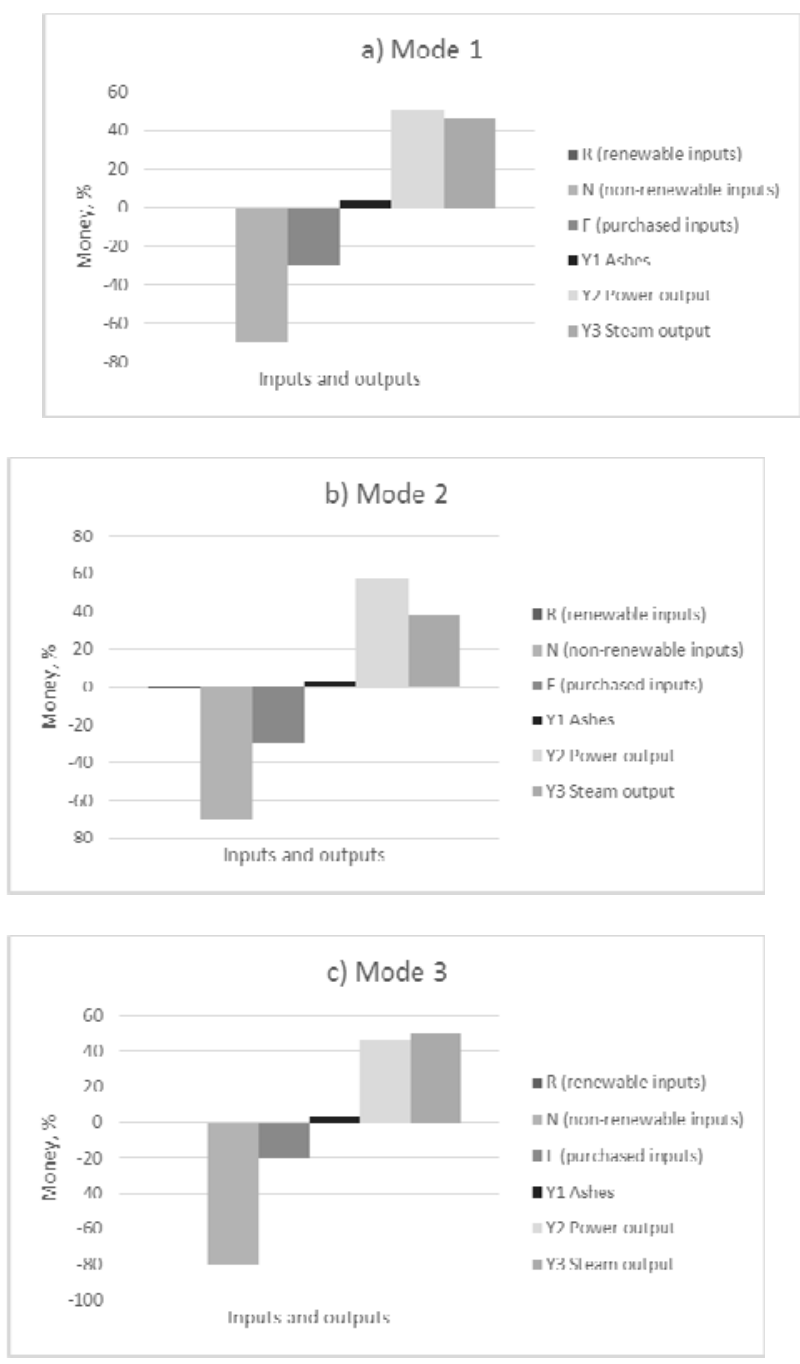

Fig. 4. Economical evaluation of three operation modes

Graphical illustration of economical cost benefit analysis is presented for three CHP operation alternative solutions (see Figure 4). Income from 
energy and ashes sold are taking place above horizontal axes (positive value). Costs of fuel, water, materials etc. in this case are placed under $\mathrm{x}$ axes as negative value. Presentation of costs and benefits in percentage allow to compare shares of renewable and non-renewable resources as well as produced energy in economical balance of cogeneration plant in case of three different operational modes.

A similar procedure applies to the emergy analysis of not only power generation, but also of energy resource extraction. For example, the emergy analysis for bioethanol and biodiesel production processes, as well as power generation using household waste or landfill biogas, has been examined in the study by [16].

\section{CONCLUSIONS}

Emergy analysis is the analysis of the sustainability of energy production, allowing to determine the amount of work to be performed by the biosphere in the production of energy. Although currently the literature primarily provides emergy assessment for energy production, it is the future analysis tool for the assessment of the impact of a given product on the biosphere.

\section{ACKNOWLEDGMENT}

The work has been supported by the National Research Program 'Energy efficient and low-carbon solutions for a secure, sustainable and climate variability reducing energy supply (LATENERGI)’.

\section{REFERENCES}

[1] Brown M. T. and Ulgiati S. Emergy analysis and environmental accounting. Encyclopedia of Energy, 2004, pp. 329-354.
[2] Brown M. T. and Ulgiati S. Emergy evaluations and environmental loading of electricity production systems. J. Clean. Prod., 10. 2002, pp. 321-334.

[3] Odum H. T., Environmental accounting: emergy and environment decision making. New York: John Wiley and Sons, 1996.

[4] Brown M. T. and Ulgiati S. Emergy-based indices and ratios to evaluate sustainability: monitoring economies and technology toward environmentally sound innovation. Ecol. Eng., 9. 1997, pp. 51-69.

[5] Ulgiati S. A. Comprehensive Energy and Economic Assessment of Biofuels: When ‘Green’ Is Not Enough. CRC. Crit. Rev. Plant Sci., 20. 2001, pp. 71-106.

[6] Hau J. L. and Bakshi B. R. Promise and problems of emergy analysis. Ecol. Modell., 178. 2004, pp. 215-225.

[7] Ulgiati S., Brown M. T., Bastianoni S., Marchettini N. Emergy-based indices and ratios to evaluate the sustainable use of resources. Ecol. Eng., 5. 1995, pp. 519-531.

[8] Campbell D. E. and Garmestani A. S. An energy systems view of sustainability: Emergy evaluation of the San Luis Basin, Colorado. J. Environ. Manage., 95. 2012, pp. 72-97.

[9] Brown M. T. and Ulgiati S. Emergy Measures of Carrying Capacity to Evaluate Economic Investments. Popul. Environ., 22. 2001. pp. 471-501.

[10] Ridolfi R. and Bastianoni S. Emergy. Encyclopedia of Ecology. 2008.

[11] Neri E., Rugani B., Benetto E., Bastianoni S. Emergy evaluation vs. life cycle-based embodied energy (solar, tidal and geothermal) of wood biomass resources. Ecol. Indic., 2014, pp. 419-430.

[12] Odum H. T. Emergy evaluation. Int. Work. Adv. Energy Stud. Energy flows Ecol. Econ. 1998

[13] Arbault D., Rugani B., Tiruta-Barna L., Benetto E. Emergy evaluation of water treatment processes. Ecol. Eng., 60. 2013, pp. 172-182.

[14] Peng T., Lu H. F., Wu W. L., Campbell D. E., Zhao G. S., Zou J. H., Chen J. Should a small combined heat and power plant (CHP) open to its regional power and heat networks? Integrated economic, energy, and emergy evaluation of optimization plans for Jiufa CHP. Energy, 33. 2008, pp. 437-445.

[15] Sha S. and Hurme M. Emergy evaluation of combined heat and power plant processes. Appl. Therm. Eng., 43. 2012, pp. 67-74.

[16] Zhang G. and Long W. A key review on emergy analysis and assessment of biomass resources for a sustainable future. Energy Policy, 38. 2010, pp. 2948-2955. 